\title{
Socio Economic Barriers Young Females Face in Accessing Technical Vocational Education and Training (Tvet) in Rwanda
}

\author{
Polycarpe Nshimirimana, Mary Damas Kitula
}

\begin{abstract}
The objective of this study was to Assess the extent to which the female household's socio-economic capacity affects enrolment in TVET" in Rwanda. Females have been sensitized on the availability, benefits of TVET, and that most of them meet the required qualifications to be enrolled and yet the uptake of females to TVET remains low. Rwandans are classified in community socio economic categories known as Ubudehe. The latter refers to the longstanding Rwandan practice and culture of collective action and mutual support to solve problems within a community. It allocates each household to one of four income and poverty-related categories as basis to access mainly public services including not limited to TVET. The study analyzed the relationship of the Household socio economic status and enrolment of females in TVET in Rwanda to attempt to answer why females are not embracing TVET as a promising avenue of acquisition of professional skills. The study used both qualitative and quantitative-triangulation methodology. The study used questionnaires, FGDs, Interviews and secondary data as data sources. The respondents included 400 females, female's parents, local leaders, TVET and IPRCS staff for the KIIs. The research performed a simple linear regression analysis to find out predictor factors to enroll in TVET hence access to TVET that supplemented the correlation analysis. The study found that the household socio economic status showed very strong correlation to the enrolment of females with a $p<001$ with a negative Pearson's coefficient of $r,-.628{ }^{* *}$. The study showed that household socio economic status was statistically significant predictor of the enrolment of female in Technical Vocational Education Training, $\beta$. $-.415, t(-16.090), p<.001, R^{2}=.394$. The results revealed that the higher the level of the household socio economic status, the less the enrolment of females in the TVET Education. The results indicated that the more a household increased income and became wealthier the more negative perception "Iabelling TVET as Second best option therefore the less their kids joined TVET. The study indicated that TVET scholarship loan plays an important role in the enrolment of Females in TVET. However, it recommends the Government to adjust or remove the wealth classification (Ubudehe category) from the list of criteria considered for a student to acquire a TVET scholarship loan.
\end{abstract}

Keywords: Socio Economic Barriers, Access to TVET, Rwanda.

\section{INTRODUCTION}

Over the years, there has been steady improvement in the status of African girls and women (African Union, 2016) particularly in agency and achievement categories of empowerment (United Nations, 2015). The weight of poverty falls most heavily on certain groups. Women in general are disadvantaged.

Revised Manuscript Received on August 13, 2020.

* Correspondence Author

Polycarpe Nshimirimana*, The Open University of Tanzania, Faculty of Arts and Social Sciences, Dar Es Salaam, Tanzania. E-mail: nshipoly@gmail.com

Mary Damas Kitula, Professor, The Open University of Tanzania, Faculty of Arts and Social Sciences, Dar Es Salaam, Tanzania. E-mail: marikitu@yahoo.co.uk

(C) The Authors. Published by Blue Eyes Intelligence Engineering and Sciences Publication (BEIESP). This is an open access article under the CC BY-NC-ND license (http://creativecommons.org/licenses/by-nc-nd/4.0/)
In poor households they often shoulder more of the workload than men, are less educated, and have less access to remunerative activities (World Bank; 1990). Rwanda Registered an increase of females in TVET professional skills acquisition for the last 7 years from 2011-2018. Figures showed 58.2\% - Male versus 41.8\% - Female (NISR ,2015) However, the gender stereotypes prevail among the community whereby girls and women usually enroll mostly in TVET traditional soft trades like tailoring, hairdressing, secretarial studies, nursing, food and nutrition, while boys and men on the other side dominate in traditional male occupations like carpentry, construction, motor mechanics, welding and electricity among others. Soft occupations are qualified by several researchers to be less paying compared to traditional male occupations.

The vision of Rwanda is to transform the Rwandan citizen into skilled human capital for socio economic development by ensuring equitable access to quality education and professional skills training (MINEDUC, 2013). However, if you look around today, women are woefully underrepresented in technical and vocational Educational training particularly at diploma level education.

A study that was conducted in 2006, commissioned by the UNESCO Institute of Statistics (UIS) showed girls faced more difficulties accessing secondary education and Technical and Vocational Educational Training (TVET) programs compared to boys.

It is not known how many Rwandans access to relevant initial and continuing TVET have including formal, non-formal and informal TVET. It is certain the demand greatly exceeds the current supply and that most of the young population is not reached by TVET. (TVET policy, 2008)

\section{PROBLEM STATEMENT AND OBJECTIVE}

Women were sensitized on the availability and benefits of TVET, women meet the required entry qualifications and yet the uptake of women to TVET remains low. Training institutions are in place and have space to accommodate trainees. As stipulated by WDA annual report (2013), 308 institutions have been registered by the Ministry of Education through the Workforce Development Authority.

A big number of students complete nine years basic education but cannot be absorbed by formal Secondary schools. In 2011, the potential supply of nine years basic education to senior six leavers only $37 \%$ was enrolled (WDA, 2013). This showed that a big percentage was idle without skills making them unemployable.

Published By:

Blue Eyes Intelligence Engineering \& Sciences Publication

(C) Copyright: All rights reserved.

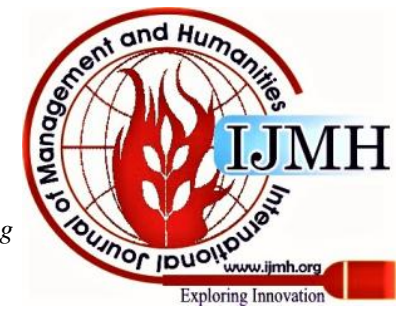


This figure was dominated by young female. Despite all these opportunities being available, the enrolment rates of females in TVET remain low. The question is why don't females embrace technical and vocational skills?

The research question was about the extent to which household socio economic status affects enrolment of females in TVET in Rwanda. The specific study objective was to assess the extent the household's socio-economic capacity affects enrolment in TVET. Throughout the literature review, researchers consistently highlighted the low participation of females in technical education. The literature review did not answer what are the causes of the low enrolment? The purpose of this research was to answer why females are not embracing TVET as a promising avenue of professional skills acquisition as a pathway to gainful employment. The study assessed the household socio economic status and enrolment of females in TVET.

\section{RESEARCH METHODOLOGY}

This study was descriptive adopting a cross-sectional study Design. The study applied both qualitative and quantitativetriangulation approaches. The study collected quantitative data, collated, analyzed, and interpreted the data systematically.

The study used various analysis techniques including descriptive analysis comparing percentages of the variables under study that helped in long run to find out the relationship of the variables. The research further explored the correlation between variables i.e. Independent Variables and dependent variables by calculation of correlation coefficient: using Pearson's (r) that showed the degree to which one, two or more variables are related.

Five degrees of correlation were used to take decision namely; perfect as first degree of correlation which is used when the value of $r$ is near \pm 1 ; high degree used when the coefficient value lies between \pm 0.50 and \pm 1 , and is considered as a strong correlation; moderate degree used when the value lies between \pm 0.30 and \pm 0.49 , and is considered as medium correlation; low degree used when the value lies below +0.29 , and is considered as a small correlation and finally no correlation when the value is zero(Cohen 1988, 1992).

\section{FINDINGS AND DISCUSSIONS}

To assess the extent to which household socio-economic capacity affect female enrolment in TVET. The study investigated female's household socio economic status in terms of household poverty classification Ubudehe including assets, income, property like land and female enrolment in TVET.

The study checked the correlation between parent's household poverty level comprising the economic capacity of the family namely income and assets to bear the TVET education costs of their females and Enrolment of females in TVET.

Households were categorized based on their social economic status and their property in terms of land and other belongings and what the family breadwinners do to earn a living. They were categorized as follows:

Table I. Ubudehe Classification

\begin{tabular}{|c|c|c|}
\hline S/N & Ubudehe Category & Description \\
\hline 1 & Category one & Families who do not own a house and can hardly afford basic needs. \\
\hline 2 & Category two & $\begin{array}{r}\text { Those who had a dwelling of their own or were able to rent one but rarely get full } \\
\text { time jobs. }\end{array}$ \\
\hline 3 & Category three & $\begin{array}{r}\text { Those who were having a job and farmers who go beyond subsistence farming to } \\
\text { produce a surplus which can be sold. The latter included the ones with small and } \\
\text { medium enterprises who could provide employment to dozens of people. }\end{array}$ \\
\hline 4 & Category 4: & $\begin{array}{r}\text { Those who owned large scale businesses, individuals working with international } \\
\text { organizations and industries as well as public servants. }\end{array}$ \\
\hline
\end{tabular}

Source: LODA (2014)

The household social economic capacity dictates family spending in relation to education of their children or family members. In normal circumstances a household start by satisfying basic needs such as food, shelter, water, and clothes. It is after the primary vital needs' satisfaction that the household if the funds are available the children will be sent TVET training centers. Generally, first and second categories of Ubudehe hardly satisfy primary needs hence the cost of education of kids is paid after the first ones are fulfilled. In a situation where resources are scarce males are prioritized more than female children to enroll in TVET.

As the household graduates through Ubudehe categories two to three and so forth, family's education investment is given much more value, both at the household and general community as well. Households of low-income generally meet basic needs including physiological (food, water, clothes) and do fail to generate wealth that help to cater for education and other expenses. Households with good and higher income generate wealth and assets that help to meet primarily basic needs at the same time be able to spend beyond the basic needs of high comfort.

In normal circumstances the higher the income the higher chances of taking children to school. However, in TVET low level Vocational Training Centers with less privilege there is a progress towards a fair gender distribution though the stereotype is still observed in labeled male reserved areas and female's reserved trades. The Ubudehe category one and two are most observed due to the cost affordability.

As the TVET level upgrades, the cost of education increases the Ubudehe category one and two households are left out and a part of Ubudehe category three. It has been noted that the higher the household's income increases, the higher the mistrust of TVET as first choice quality education hence parents enrolling their kids decreases mostly for wealthier households in category three and four for example.

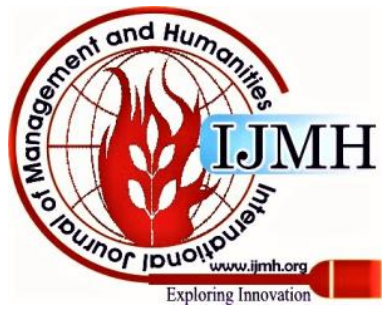


Females are more affected than males. These were observed in diploma and advanced diploma levels registered females, especially in engineering courses. The study found out a negative correlation between Ubudehe classified household in terms of economic and social status and enrolment of females. Below were the results:

Table II. Correlation of Ubudehe Classification Household Income and Enrolment

\begin{tabular}{|c|c|c|c|}
\hline \multicolumn{2}{|c|}{} & $\begin{array}{c}\text { Enrolment } \\
\text { status }\end{array}$ & Ubudehe F category \\
\hline \multirow{3}{*}{ Enrolment status } & Pearson Correlation & 1 & $-.628^{* *}$ \\
\cline { 2 - 4 } & Sig. (2-tailed) & & .000 \\
\cline { 2 - 4 } & $\mathrm{N}$ & $-.628^{* *}$ & 400 \\
\hline \multirow{3}{*}{ Ubudehe F category } & Pearson Correlation & .000 & 1 \\
\cline { 2 - 4 } & Sig. (2-tailed) & 400 & 400 \\
\cline { 2 - 4 } & $\mathrm{N}$ & \\
\hline
\end{tabular}

Source: Field study result (2016)

The level of household socio economic status Ubudehe classification showed very strong negative correlation to the enrolment of females with a $p<.001$ with a negative Pearson's coefficient of r, $-.628^{* *}$
The study explored if the household socio economic status predicted the female enrolment to TVET education. The study performed a simple linear regression analysis test below were the results:

Table III. Regression Analysis Test of Ubudehe Classification Household Income and Enrolment of Females in TVET

\begin{tabular}{|l|l|l|}
\hline & Constant & Beta $(\boldsymbol{\beta})$ \\
\hline Coefficient & 2.392 & -.415 \\
\hline $\mathrm{T}$ & 40.702 & -16.090 \\
\hline Probability & .000 & .000 \\
\hline \multicolumn{2}{|c|}{$\mathrm{F}=258.879$} \\
\hline \multicolumn{2}{|l|}{ a. Dependent Variable: Enrolment status } \\
\hline
\end{tabular}

\section{Field study results (2016)}

The study results indicated that household socio economic status was statistically significant predictor of the enrolment of female in Technical Vocational Education Training, $\beta .-.415 \mathrm{t}(-16.090), \mathrm{p}<.001, \mathrm{R}^{2}=.394$. The equation prediction resulted to the following equation below: Y (enrolment) $=2.392-.415 \mathrm{X}$

The results indicated that the higher the level of the household socio economic status, the less the enrolment $(\mathrm{Y})$ of females in the TVET Education as indicated in the regression results in table above.

Uplifting a household social economic status within the classified Ubudehe Category to the next advanced category reduce female's chances to enroll in TVET.

However, $\mathrm{R}^{2}=.394$ showed that $39.4 \%$ of the variation in dependent variable which was enrolment of female in TVET were explained by household socio economic status Ubudehe categorization. Therefore, new study needs to consider more independent variables to the model.

Beside the enrolment, numerous other studies have shown that the socioeconomic status (SES) achievement gap is the main cause of inequality of students in schools and other educational systems (Bourdieu 1989; Carnoy 2007; Shavit and Blossfeld 1993, as cited in Doren, 2013, Farid, G. and Mahbubeh, Y. 2014). The most significant reason of this finding according to Battle and Lewis (2002) might be the fact that a person's education is clearly linked to their life chances, income and well-being (Farid, G. and Mahbubeh, Y. 2014). The low status students compared with the mid/high status students are often more depressed and they are concerned about their financial problems and sometimes they don't have enough time for studying and other academic activities. (Farid, G. and Mahbubeh, Y. 2014)

The Focus Group Discussions with parents as well as females in TVET agreed that the more a household increased income and became wealthier the more negative perception "labelling TVET as Second best option therefore the less their kids joined TVET.

One of the females said:

"I registered in TVET due to my parent's limited financial capacity".

A parent and carpenter said:

"Things have evolved TVET has become expensive, I couldn't afford to pay the school dues of my daughter preferred occupation she was constrained to go in 12 years basic education subsidized by the government where the cost was affordable"

Interviewed within the Ubudehe category three classified parents a significant number of parents tended to agree on low quality of education provided in TVET.

A parent said:

"TVET lack of equipment, unqualified trainers and unattractive programs that opens to the quick employment" I do not see the need of registering, my daughter in TVET".

Published By:

Blue Eyes Intelligence Engineering \& Sciences Publication

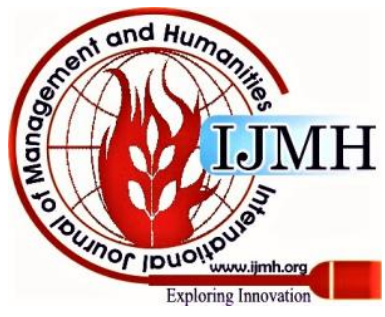


Parents discussed within Ubudehe category four, majority of them have negative perceptions about the TVET. One of them stated in the following terms: "Liked or not TVET is for the second-class education".

Another one revealed:

"Unless my financial capacity defaults, I will send my female kids to the good general education schools.

A TVET expert interviewed said:

"There is inadequate distribution of economic opportunities attracting best TVET Training centers to the poles of capital City, secondly cities and other Cities". Added:

"Remote district areas affect female's education due to their less mobility, increasing TVET cost for transporting them to reach best TVET colleges most of them located in cities daily, where boarding is less promoted."

Nyamagabe and Nyamasheke districts parents said:

"We have young people craving of skills but cost of TVET is a limitation factor to register them to good TVET schools" revealed by parents during interviews and Focus group Discussions. A wealthier parent in Gasabo District interviewed why her daughter didn't register in TVET, She responded: "The general education pathway offers the opportunity for learners to move to Bachelors, Masters and $\mathrm{PhD}$ programs in public or private universities in Rwanda. While finishing TSS offers the opportunity to trainees to go through a one-year certificate program or a two-year diploma program or a three-year advanced diploma program I see it as cutting her education dream to touch the sky". TVET education is expensive to the aspirants, at IPRCs at the graduation they receive one year certificate to advanced diploma after one to three years of education of which the tuition fee was equivalent to 730 USD per year (2016) compared to GDP per capita of US\$697 in 2015 (World Bank Indicator, 2016), that money was high to the population classified in Ubudehe category one, two and a big part of the category three that compose more than $80 \%$ of the potential candidates to TVET. Since 2011, the Rwanda Education Board (REB) has been administering the student loans scheme for tertiary level students, including students in TVET and university under its Higher Education Student Loans Department. Loans are granted to students based on (a) program the students plan to enroll in (40 percent of total score); (b) academic performance (40 percent of total score); and (c) financial means testing or the Ubudehe status of the student (20 percent of total score). Only self-sponsored students and students in Ubudehe category 4 (the wealthiest category) are charged full tuition fees. Students in Ubudehe categories 1-3 as long as they fulfill the first two conditions their tuition fees and living allowances are given in loans subject to availability of budget. Students in category four are not considered for student loans. The study indicated in one of the biggest IPRC campus for the year 2016 there was not even one student registered from Ubudehe category four. Interviewed one male parent the reason why? Here was his response:

"I found TVET expensive, I am classified in the Ubudehe category four TVET is self-sponsored coupled with the fact that TVET is second class education which I do not like at all". Focus Group Discussion held with parents from Ubudehe category one, two and three most of them confirmed the fact that TVET education is expensive such as the Integrated Polytechnic Regional Center which is the college level delivering to the advanced diploma compared to their income and socio-economic status. A student at IPRC said:

"To be honest I could not afford TVET school fees I do thank the government for the scholarship loan".

Another one said:

"I do not see a student from Ubudehe Category one selfsponsored registering in TVET College while meeting basic needs is still challenging".

\section{CONCLUSION}

The study results indicated that household socio economic status was statistically significant predictor of the enrolment of female in Technical Vocational Education Training, $\beta$. -.415, $\mathrm{t}(-16.090), \mathrm{p}<.001, \mathrm{R}^{2}=.394$. The results revealed that the higher the level of the household socio economic status, the less the enrolment of females in the TVET training. Rich parents only send their kids to Integrated Polytechnic Regional Centers if they are Government sponsored. The poorer the families are the less the girl's enrolment to TVET particularly at the Diploma level due to limited resources; to the most if any resource available; it is the boys who will be sent to TVET training from such families. Besides the enrolment, various other studies have shown that the socioeconomic status (SES) achievement gap is the main cause of inequality of students in schools and other educational systems (Bourdieu 1989; Carnoy 2007; Shavit and Blossfeld 1993, as cited in Doren, 2013, Farid, G. and Mahbubeh, Y. 2014). The most significant reason of this finding according to Battle and Lewis (2002) might be the fact that a person's education is clearly linked to their life chances, income and well-being (Farid, G. and Mahbubeh, Y. 2014). The low status students compared with the mid/high status students are often more depressed and they are concerned about their financial problems and sometimes they don't have enough time for studying and other academic activities. (Farid, G. and Mahbubeh, Y. 2014) Poverty in the society is a major factor that made the girl child not to go to school or stopped schooling. The prevailing economic hardship constraints parents' financial support for education. In such a situation, the overriding interest is on sustaining the source of livelihood rather than supporting girl the child education (Adebola, H ; Anyachebelou, F.E. and Madu, C.O.2012) The study noted that "If the TVET scholarship is a loan, it should be provided to whoever wanted irrespective of Ubudehe category classification. The government should readjust its policy."

The Government TVET scholarship loan disbursed based on the applicant classification in Ubudehe category denied to the student the fundamental right of education.

As stated in the universal declaration of human rights charter in the article 26; everyone has the right to education. Education shall be free, at least in the elementary and fundamental stages. Elementary education shall be compulsory. 
Technical and professional education shall be made generally available and higher education shall be equally accessible to all on the basis of merit (United Nations General Assembly, 1948).

Girls due to their household economic limitations fail to access their education rights at given level of TVET Education. Girl's fundamental human rights such as education are compromised. The situation makes them less participative to their full potential in the socio economy of their communities.

The key to girl's progress is education and training. Education is an indispensable means of realizing other human rights. As an empowerment right, education is the primary vehicle by which economically and socially marginalized children can lift themselves out of poverty and obtain the means to participate fully in their communities (Adebola, H; Anyachebelou, F.E. and Madu, C.O. 2012).

The study also concurred with the study of Rena, R (2007) on Factors Affecting the Enrollment and the Retention of Students at Primary Education in Andhra Pradesh with regard to the never enrolled children, the parents stated that due to their inability to afford education on account of their inadequate income, they have not enrolled their kids at primary school. Again, the parents admitted that they discriminated against their girls.

This study is in line with UNICEF Situation analysis of Children in Rwanda (2018), where it found that although the enrolment in both TVET and tertiary education has increased, women are underrepresented, and participation is strongly skewed in favor of wealthy and urban populations.

\section{REFERENCES}

1. Adebola, H., Anyachebelu, F.E., \& Madu, C.O. (2012). Towards empowerment of the Nigerian girl child, the socio-cultural diagnosis. Journal of Educational and Social Research, 2(3), 29-35

2. Carla, K. (2013). Educate Girls, Develop Nations [Blog post] Retrieved from http://blog.usaid.gov/2013/04/educate-girls-developnations/.

3. Chepchieng, M. C., \& Kiboss, J. K. (2004). Influence of family socio-economic status and gender on students' academic performance. Journal of Education and Human Resource, 2 (2), 50-62.

4. Fafchamps, M. \& Quisumbing, A. (2005). Assets at Marriage in Rural Ethiopia. Journal of Development Economics, 77, 1- 25.

5. Farid,G. \& Mahbubeh, Y. (2014). The relationship between Socioeconomic status and academic achievement in the EFL classroom among Iranian university students. European Journal of English Language and Literature studies 2(1), 49-57.

6. Government of Rwanda, (2012). Rwanda Vision 2020, revised 2012 July (2000). Pp 40

7. National Institute of Statistics of Rwanda, (2013). Statistical yearbook 2012. Government printer, Kigali, Rwanda. Pp 154

8. Rena, R. (2007). Factors affecting the enrollment and the retention of students at primary education in Andhra Pradesh - a village level study. Essay in Education UGSM Monarch Business School, 1, (22), 28, 102-112 pp.

9. Rwanda Ministry of Education. (2008). Technical and Vocational Education and Training (TVET) Policy. Kigali, Rwanda. Government printer, Kigali, Rwanda. Pp12

10. Rwanda Ministry of Education. (2015). Technical and Vocational Education and Training (TVET) Policy. Kigali, Rwanda. Government printer, Kigali, Rwanda. Pp13

11. Rwanda Ministry of Education. (2015). Technical vocational education and training strategic plan 2015/16-2017/18. Government printer, Kigali, Rwanda. Pp 15

\section{AUTHORS PROFILE}

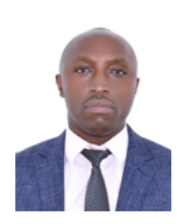

Polycarpe Nshimirimana is a Public Private Partnerships Expert prior He was a part time lecturer Module Leader at University of Rwanda 2012-2014 in Management of Development Projects. He is pursuing PhD in Faculty of Arts and Social Sciences with Open University of Tanzania. He pursues the growth of knowledge in the discipline of Technical and Vocational Educational Training (TVET).

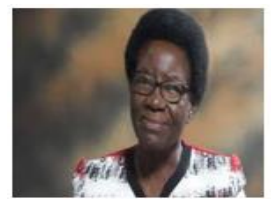

Mary Damas Kitula (Professor) BA (Ed), MA (Demography) UDSM; PhD (Sociology, Demography and Environment). Senior lecturer at the Open University of Tanzania, She is a coordinator for master's Program Gender Studies at Open University of Tanzania 